\section{PERFECTLY MIXED CAPSULES}

GC's Silver Mix electronic mixing machine is the perfect device to mix all of your Fuji capsules.

Silver Mix operates with an 'eight' type vibration ideal for all amalgam capsules, composites and other encapsulated dental materials. Thanks to the safety cover and adjustable timer, every type of capsule will be mixed to perfection every time. This reliable machine is quiet with little vibration so will not distract the operator during use.

To mix your pre-dosed capsules simply place the capsule in the Silver
Mix holder and close the safety lid. Press the 'set' button to adjust the time in increments of ten seconds. Press the start button and the machine will do the rest for you. An audible beep lets you know that your capsule is mixed and ready to use.

GC's range of Fuji glass ionomers are available in capsulated presentations which offer your advantages over the hand mixed versions. Each capsule contains the precise amount of liquid and powder needed to ensure the perfect consistency every time, plus the angled nozzles on Fuji capsules allow you to easily and quickly place the material exactly where you want it.

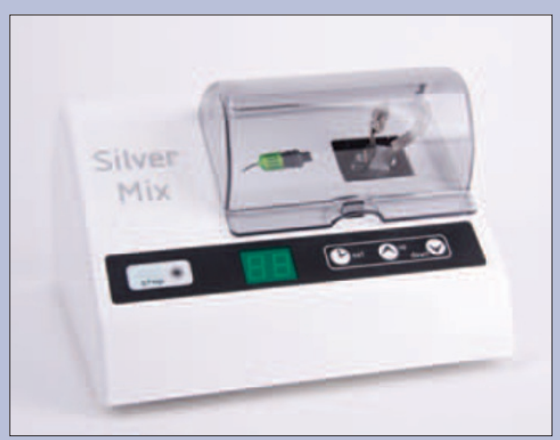

Silver Mix is available free of charge on the purchase of any combination of eight boxes (50 capsules) of Fuji glass ionomers through your dental dealer. For further information contact GC UK on 01908218999.

\section{FACE THE CHALLENGE}

In an effort to help practices face the challenges of the coming year, Henry Schein Minerva has identified 12 practice building areas in which they can help practices optimise their business potential and has launched the Henry Schein Minerva 2012 Face the Challenge promotion.

Face the Challenge will run for the first six months of the year and gives practices who work with Henry Schein Minerva in three practice building areas the opportunity to qualify for fantastic rewards. For those who qualify in at least five areas there is the chance to win a holiday worth thousands of pounds.

\section{STREAMLINED DESIGN}

Bearing all the hallmarks of Castellini's unrivalled quality, the Skema 6 combines an ergonomic, stylish design with outstanding performance. The Skema 6 enables instruments to be used for surgical and specialist procedures, whilst guaranteeing operating safety.

Thanks to its flexibility and functional design, the Skema 6 creates an ideal working space, enabling assistants to interact smoothly without hindering the dentist's progress. By lightly touching the capacitive sensor inside the handle
Henry Schein Minerva has expertise across a wide range of products and services and the breadth of this offering is reflected in the 12 practice building areas which include decontamination, education, service packages, practice management software and consumable products. Whatever you buy from Henry Schein Minerva it all counts, enabling practices to enjoy the benefits of a fully integrated business solution that will help improve all-round performance.

If you would like to face the challenge, simply visit the website www.successwithhsm.co.uk, register and start performing. Or for more information call 08700102043.

on the dentist's module, instruments can be easily and efficiently repositioned. With its streamlined design, everything is within reach, enabling the dentist to focus on the patient while reducing physical stress.

With extensive travel arms, the Skema 6 adjusts to each clinical situation in the most efficient way possible, whilst the adjustable footrest (made of antibacterial material) can be extended and removed for total disinfection.

Dentists can rely on Castellini quality. For more information, call RPA Dental on 08000933975 or visit www.castellini.com.

\section{INTEGRATED, PAPERLESS PRACTICES}

Digital Dental believe that high quality digital imaging is a cornerstone for successful periodontology, enabling dentists to perform an accurate and reliable diagnosis and monitor progress throughout the course of treatment. Digital Dental provide unbiased advice enabling dentists to choose the right products for their individual digital imaging needs.

With over 14 years' experience, they appreciate every practice is different and has individual requirements. They offer a range of high quality digital systems, enabling their clients to integrate the most appropriate digital tools into their practices. Not restricted to one or two manufacturers, Digital Dental's products can integrate with any practice management software to deliver seamless integration and paperless practices.

Their technically trained advisers demonstrate, install and train their clients on the selected equipment. They can demonstrate everything at one visit and at times to suit the practice, including 'live' demonstrations, not mock ups on dummy systems. They then install the equipment and provide comprehensive free hardware and software training.

Telephone Digital Dental on 0800027 8393,email sales@digitaldental.co.com or visit www.digitaldental.uk.com. 